\title{
Evaluation of Aflatoxin B1 and Patulinin Blood of Iraqi Renal Failure patients
}

\author{
Basaad Abdzaid AL-Fatlawi \\ Department of Biology, Faculty of Science, University of Kufa,Najaf, Iraq
}

\begin{abstract}
Objectives: The current study aimed to investigate and evaluatethe Aflatoxin B1 and Patulin in blood samples of patients with Renal Failure.

Method: Hundred fifty blood samples collected from patients with Renal Failure were included in this study. The agerange of patients was 1-61 years. Toxin extraction from the samples was done by Thin Layer Chromatography technique (TLC).

Results: There were 100 from 150 samples of blood containedAflatoxinB1and Patulin. The highest percentage blood samples contamination with Aflatoxin B1 was (18.181\%) at age group (11-30) years and Patulin was (20\%) that collected from persons at age group (11-20) years, the percentage of blood samples that contamination withAflatoxin B1 and Patulin that collected from the female was (52.727\% and 53.33\%).

Conclusion: Persons in Najaf province high exposure to mycotoxins from foods (apples,pear and peach) that present in local markets, that are contaminated with mycotoxins. This suggests that these mycotoxins may be a risk factor of renal failure.
\end{abstract}

Keyword: Mycotoxin, Aflatoxin, Patulin,Thin Layer Chromatography.

\section{Introduction}

In human and animals, Mycotoxins are secondary metabolites of moulds. The toxic effect of mycotoxins in human is called mycotoxicosis. Mycotoxicosis severity depends on the toxicity of mycotoxin, the duration of exposure, the characteristic feature of individual. In general, the mycotoxins are organic molecules with low molecular weight ${ }^{1}$. Aspergillus molds produce mycotoxin knows as Aflatoxin. It is predominant mycotoxin in addition to trichothecene, due to their highly toxicity and their carcinogenic effects ${ }^{2}$. In high humidity and temperature conditions, Aflatoxins present predominantly in rice, nuts, and cereals.Both of A. flavus, and A. parasiticus, are the Aspergillus species producing $\mathrm{B}$ and $\mathrm{G}$ aflatoxins ${ }^{3}$. In the southern USA, in 1952, because of the consumption of mouldy corn by swine caused an outbreak of 'moldy corn toxicosis. Also, in Turkey in 1960 there was another outbreak, Turkey ' $X$ ' disease. Actually, Aflatoxins are powerful hepatocarcinogens produced by A. nomius, Aspergillus flavus, and A. parasiticus. Anorexia, lethargy, muscle weakness, liver haemorrhages and necrosis, engorged kidneys and liver cancer are their symptoms ${ }^{4}$.

During the 1940, Patulinwas first isolated via antimicrobial active principle from Penicillium patulum latercalled P.urticae, now P. griseofulvum ${ }^{5}$. In previous studies, the blue mold P.expansum, that causes softrot of fruits, was recognizedas one of the most common offenders in patulin contamination. It is commonly present in unfermented fruit juice, althoughit does not survive the fermentation into cider products. Remarkably, Patulin is toxic at high concentration ${ }^{6}$ . Chemically, Patulin is a polyketide lactone. Fungal species of Penicillium, Aspergillus and Byssochlamys growing on fruit and vegetables, cereal grains and silage produce Patulin ${ }^{7}$. Throughout the world, Chronic Kidney Disease is the third most common disease ${ }^{8}$. It is affecting ten percent of the world's population; it is related with poor quality of life ${ }^{9}$. Prevention and determination the risk factor of renal Failure become the major goal for many studies ${ }^{10}$. Therefore, the aim of this study was to evaluate the Aflatoxin B1 and Patulin Iraqi renal Failure patients. 


\section{Materials and Method}

The study protocol was approved by University of Kufa, College of Science. One hundred fifty blood samples collected from Iraqi renal failure patients visited Dialysis unit at Al-Sadder Medical City, in Iraq. The entire participant or their parents approved performing the study. The range of age of the patients was 1- 61 years. Blood samples were collected in gel tube and transported to laboratory.

Extraction of Aflatoxin B1 and Patulin were carried by placing the tubes containing the blood into the centrifuge 6000 RPM to spread the serum. Sera were separated. To each sample one drop of proteinase $\mathrm{K}$ (BioBasic, Canada) were added. After the addition of the enzyme, the tubes were placed in water bath $35^{\circ} \mathrm{C}$ for $10 \mathrm{~min}$. The mixture was the exposed to centrifugation in 8000 RPM for 3 mints, the supernatant were taken and the deposit were leaved. The filter double volume from chloroform and well mixed as it formed two layers. Were used to extract Aflatoxin B1 and Patulin,chloroform layer and serum layer thenThe chloroform layer was withdraw and Put in a small, clean and sterile tube.

Detection of Aflatoxin B1 andpatulin; Thin Layer Chromatography (TLC)technique were used in detection of patulin serum. Thin Layer Chromatography plates were putted in oven at $120 \mathrm{C}^{\circ}$ for one hour to activate it. Straight line was made on TLC plate in distance of about $1.5 \mathrm{~cm}$ from the base plate. Patulin stander (15 $\mu \mathrm{l})$ was putted as spot on TLC plate by capillary tube and putted $15 \mu 1$ on plate from each extracted samples with a distance $2 \mathrm{~cm}$ between sample and another then let the spots to dry in laboratory condition. Separation tank was used that containing $100 \mathrm{ml}$ from mixture chloroform: acetone in a ratio 8:2. The plate exited from the tank and leaved it to dry under the laboratory condition. Then plate examined under UV light (360 nm) and compared the color and RF(Relative Flow) of extracted samples with the standard toxin.

Qualitative investigation of Aflatoxin B1 and patulin in blood UV visible spectrophotometer were depended it to qualitative investigation of Aflatoxin B1 and patulin. A standard curve was drawn to absorption for different concentrations of standard Aflatoxin and patulin,the standard concentrations were $1,2,3,4,5,6,7$, and $8 \mu \mathrm{g} / \mathrm{L}$. The unknown concentrations of toxin in the blood were determined from the standard curve $\mathrm{e}^{11}$.

\section{Result}

The result showed $66.666 \%$ of renal failure patients infected (36.666\% Aflatoxin, and 30\% patulin toxin), also, $33.333 \%$ not contaminated with Aflatoxin and patulin as in Table 1.

Also this study clarified that highest percentage of patients with Aflatoxin at age 11-30 years, While, $18.181 \%$ of patients with Aflatoxin at age 41-50\%years. As shown in Table 2.

The result in Table 3 high light the fact that the infected female patients percent were $(52.727 \%$, $53.333 \%)$, while the infected male patients percent were $(47.272 \%, 46.666 \%)$ infected with Aflatoxin and patulin respectively.

Table 1: Number and percentage of samples blood of persons borne Renal failure contamination and noncontemned with Aflatoxin and patulin toxin.

\begin{tabular}{|l|c|c|}
\hline Case & Number of Patients & Percentage (\%) \\
\hline Number of persons non bore toxin & 50 & 33.333 \\
\hline Number of persons bore Aflatoxin & 55 & 36.666 \\
\hline Number of persons non bore patulin & 45 & 30 \\
\hline
\end{tabular}

Table 2: Effect of age on contaminated patients with renal failure with Aflatoxin and patulin toxin.

\begin{tabular}{|c|c|c|c|c|}
\hline Range of age (years) & $\begin{array}{c}\text { No. of patients borne } \\
\text { Aflatoxin }\end{array}$ & Percentage (\%) & $\begin{array}{c}\text { No. of patients borne } \\
\text { Patulin }\end{array}$ & Percentage (\%) \\
\hline $1-10$ & 8 & 14.545 & 7 & 15.555 \\
\hline $11-20$ & 10 & 18.181 & 8 & 17.777 \\
\hline $21-30$ & 10 & 18.181 & 7 & 15.555 \\
\hline
\end{tabular}




\begin{tabular}{|c|c|c|c|c|}
\hline Range of age (years) & $\begin{array}{c}\text { No. of patients borne } \\
\text { Aflatoxin }\end{array}$ & Percentage (\%) & $\begin{array}{c}\text { No. of patients borne } \\
\text { Patulin }\end{array}$ & Percentage (\%) \\
\hline $31-40$ & 7 & 12.727 & 7 & 15.555 \\
\hline $41-50$ & 9 & 16.363 & 9 & 20 \\
\hline $51-60$ & 5 & 9.090 & 3 & 6.666 \\
\hline $61<$ & 6 & 10.909 & 3 & 6.666 \\
\hline
\end{tabular}

Table 3: Gender of patients effects on Aflatoxin and patulin toxin.

\begin{tabular}{|c|c|c|c|c|}
\hline Gender & $\begin{array}{c}\text { No. of patients borne } \\
\text { Aflatoxin }\end{array}$ & Percentage (\%) & $\begin{array}{c}\text { No. of persons borne } \\
\text { Patulin }\end{array}$ & Percentage (\%) \\
\hline Male & 26 & 47.272 & 21 & 46.66 \\
\hline Female & 29 & 52.727 & 24 & 53.33 \\
\hline
\end{tabular}

\section{Discussion}

Worldwide, chronic consumption foods contaminated with aflatoxin is the major problem for human and animals, especially in developing countries ${ }^{12}$.

Previous studies reported that Aflatoxins disturb numerous body organs, such as heart, skeletal muscles, endocrine organs, lung, brain, liver and kidneys. Because more than $20 \%$ of blood in circulation reaching to the kidneys theyare susceptible to high concentration of toxic agent in the blood ${ }^{13-15}$.

Also, the kidneys require high nutrients and oxygen, since their load of work ${ }^{16}$. Various segments of nephrons are attached by aflatoxins in addition to its metabolites. The possible reason, the aflatoxin prompts protein reduction so increases the kidney cells necrosis ${ }^{17}$. Previous studies reported that exposer to aflatoxins induced kidney syndromes ${ }^{18}$, deteriorating variations in renal tubular cells in addition to unusual change of glomerular epithelial cells ${ }^{19}$. Other studies, on animals predicted that there was decreasing in the GFR, reabsorption of glucose and organic anions in animal's exposer to the aflatoxins ${ }^{20}$.

Numerous hostile health special effects causing from exposure to patulin have been labelled previously. Actually, patulin is stated to be very cytotoxic, genotoxic, neurotoxic, and immunosuppressive. Because, Patulin has a high affinity for sulphydryl groups in the proteins ${ }^{21}$. The major Kidneys function are maintain of total body salt, acid base balance and blood volume regulation, in addition to excretion metabolic waste products ${ }^{19}$. Accordingly, the levels of the toxic substance in the lumen and surrounding renal cells are fairly high making it a possible target for patulin induced toxicity ${ }^{22}$.

The data of the present study indicate that there are high percent of patient with renal failure contaminated with aflatoxin and Patulin in Iraq. This suggests that these mycotoxins may be a risk factor of renal failure.

\section{Conclusion}

Persons in Najaf province high exposure to mycotoxinsfrom foods (apples,pear and peach) that present in the local markets, that are contaminated with mycotoxins. This suggests that these mycotoxins may be a risk factor of renal failure.

\section{Funding Sources: Self.}

Conflicts of Interest: Declared none.

Ethics Statement: This experiment was approved by the Central Committee for Bioethics in college of Sciences, University of Kufa, Iraq.

\section{References}

1. Mostrom, M. S., \& Jacobsen, B. J. Ruminant Mycotoxicosis: An Update. Veterinary Clinics: Food Animal Practice 2020; 36(3), 745-774.

2. Singh, A., Deepika, Chaudhari, A. K., Das, S., Prasad, J., Dwivedy, A. K., \& Dubey, N. K. .Efficacy of Cinnamomum cassia essential oil against foodborne molds and aflatoxin B1 contamination. Plant Biosystems-An International Journal Dealing with all Aspects of Plant Biology 2020; 1-9.

3. Smith,J.E.;Solomons,G.; Lewis,G. and 
Anderlson,J.C. Natural toxins . Bio.Sci.Biotechnol 1994; 3(4):187-192.

4. 4-Williams,J.H.;Philips,T.D.;Jolly,P.E.;Stiles,J.K.; jolly,C.M. and Aggarwal .D. Human afltoicosis in developing countries and a review of toxicology,exposure,potential health consequences and interventions. Am.j.Clin.Nutr 2004; 80: 11061122.

5. Pitt, J. I., \& Miller, J. D. A concise history of mycotoxin research. Journal of agricultural and food chemistry 2017; 65(33), 7021-7033.

6. Frisvad, J. C. A critical review of producers of small lactone mycotoxins: patulin, penicillic acid and moniliformin. World Mycotoxin Journal 20181; 11(1), 73-100.

7. Perrone, G., \& Susca, A. Penicillium species and their associated mycotoxins. In Mycotoxigenic Fungi 2017; (pp. 107-119). Humana Press, New York, NY.

8. Sanyaolu, A., Okorie, C., Annan, R., Turkey, H., Akhtar, N., Gray, F., \& Nwaduwa, I. C. Epidemiology and management of chronic renal failure: a global public health problem. Biostatistics Epidemiol Int J 2018; 1(1), 00005.

9. Adhikari, S., Shrestha, S., Shakya, R., \& Koirala, N. Prevalance of Chronic Complications and Drug Utiliza-tion Pattern of Type II Diabetes Mellitus. MJ Diab 2017; 2 (1): 006. Citation: Adhikari S, Shrestha S, Shakya R and Koirala, (2017).

10. Nima R. S., Aziz D. Z. The Oxidative Stress Induced by the Vapours of Electronic- Hookah on Mice Liver Tissues.Sys Rev Pharm 2020;11(9):420-423.

11. Proget, C.M. Food mycotoxins :An update. Food Sci 2011;.71:51-65.

12. Aristil, J., Venturini, G., Maddalena, G., Toffolatti, S. L., \& Spada, A. Fungal contamination and aflatoxin content of maize, moringa and peanut foods from rural subsistence farms in South Haiti. Journal of Stored Products Research 2020; 85, 101550.

13. Fouad, A. M., Ruan, D., El-Senousey, H. K., Chen, W., Jiang, S., \& Zheng, C. Harmful effects and control strategies of aflatoxin b1 produced by Aspergillus flavus and Aspergillus parasiticus strains on poultry. Toxins 2019; 11(3), 176.

14. Solis-Cruz, B., Hernandez-Patlan, D., Petrone, V. M., Pontin, K. P., Latorre, J. D., Beyssac, E., ... \& Lopez-Arellano, R. Evaluation of a bacillus-based direct-fed microbial on aflatoxin b1 toxic effects, performance, immunologic status, and serum biochemical parameters in broiler chickens. Avian diseases 2019; 63(4), 659-669.

15. Solis-Cruz, B., Hernandez-Patlan, D., Petrone, V. M., Pontin, K. P., Latorre, J. D., Beyssac, E., ... \& Lopez-Arellano, R. Evaluation of a bacillus-based direct-fed microbial on aflatoxin b1 toxic effects, performance, immunologic status, and serum biochemical parameters in broiler chickens. Avian diseases 2019;63(4), 659-669.

16. Lunyera, J., Davenport, C. A., Jackson, C. L., Johnson, D. A., Bhavsar, N. A., Sims, M., ... \& Ricardo, A. C. Evaluation of allostatic load as a mediator of sleep and kidney outcomes in black Americans. Kidney international reports 2019; 4(3), 425-433.

17. Saleemi, M. K., Ashraf, K., Gul, S. T., Naseem, M. N., Sajid, M. S., Mohsin, M., ... \& Khan, A. Toxicopathological effects of feeding aflatoxins B1 in broilers and its ameliosration with indigenous mycotoxin binder. Ecotoxicology and environmental safety 2020; 187, 109712.

18. Badr, A. N., \& Naeem, M. A. Protective efficacy using Cape-golden berry against pre-carcinogenic aflatoxins induced in rats. Toxicology Reports 2019; 6, 607-615.

19. Alonso-Garrido, M., Tedeschi, P., Maietti, A., Font, G., Marchetti, N., \& Manyes, L. Mitochondrial transcriptional study of the effect of aflatoxins, enniatins and carotenoids in vitro in a blood brain barrier model. Food and Chemical Toxicology 2020; 137, 111077.

20. Ayo, E. M. Potential of Tanzanian local clay and ash based materials for binding aflatoxins in animal feeds 2020; (Doctoral dissertation, NM-AIST).

21. Abbasi, A., Babaali, E., \& Berizi, E. Effect of radiation, heating, high pressure, and the commercial processing method on reduction and/ or elimination of patulin in fruit and vegetable products: a systematic review. Toxin Reviews 2019; 1-9.

22. Tokarova, K., Vasicek, J., Jurcik, R., Balazi, A., Kovacikova, E., Kovacik, A., ... \& Capcarova, M. Low dose exposure of patulin and protective effect of epicatechin on blood cells in vitro. Journal of Environmental Science and Health, Part B 2019;54(6), 459-466. 